\title{
Capsule Commentary on Alford et al., Primary Care Patients with Drug Use Report Chronic Pain and Self-Medicate with Alcohol and Other Drugs
}

\author{
William C. Becker, MD \\ Section of General Internal Medicine, VA Connecticut Healthcare System, Yale University School of Medicine, New Haven, CT, USA.
}

J Gen Intern Med 31(5):533

DOI: $10.1007 / \mathrm{s} 11606-016-3621-6$

(c) Society of General Internal Medicine 2016

I

$\mathrm{n}$ this issue of JGIM, Alford and colleagues report on a I phenomenon that is already of major significance to generalists and their patients (and only likely to become increasingly so): the co-occurrence of chronic pain and substance use, misuse and substance use disorders. ${ }^{1}$ This work appropriately sounds the alarm that our treatment strategies, and, upstream, education and training of current and future generalists, needs to be responsive to the current reality and ongoing trend. It also advances methodological work in exploring one of the hypothesized direct pathways between pain and substance use: self-medication.

Alford et al. found that among nearly 600 adult patients in an urban primary care setting who screened positive for any illicit drug use or prescription drug misuse, chronic pain was reported by a remarkable $87 \%$, with $13 \%$ rating that pain as mild, $24 \%$ moderate and $50 \%$ severe. Pain-related dysfunction, a more salient measure for clinical action, was reported by an even more remarkable $74 \%$ with $15 \%$ mild, $23 \%$ moderate, and $36 \%$ severe. These data are on the high end of the range of previously reported related findings, ${ }^{2,3}$ likely in part explained by differences in population studied and outcome ascertainment. However, another probable contributory explanation is that with soaring opioid prescribing in the past 20 years ${ }^{4}$ and ageing of the population, the prevalence of co-occurring chronic pain and opioid misuse (present in a significant proportion of their sample) has simply increased.
Half who used illicit drugs reported using them to treat pain. Over $80 \%$ with prescription drug misuse did so to treat pain. One potential source of lack of specificity (and thus false positivity) in this metric was the use of "pain or discomfort" in the question stem. It is conceivable, but likely rare, that respondents might have meant anxiety or discomforting distress as the target of self-medication rather than pain per se. Nonetheless, undoubtedly, these data further argue for high quality pain assessment and treatment as part and parcel with primary care's management of harmful substance use.

Corresponding Author: William C. Becker, MD; Section of General Internal Medicine, VA Connecticut Healthcare System, Yale University School of Medicine, New Haven, CT, USA (e-mail: william.becker@yale.edu).

\section{Compliance with ethical standards:}

Conflict of Interest: The Author has no conflicts of interest with this article.

\section{REFERENCES}

1. Alford DP, German JS, Samet JH, Cheng DM, Lloyd-Travaglini CA, Saitz R. Primary care patients with drug Use report chronic pain and selfmedicate with alcohol and other drugs. JGIM. 2016. doi:10.1007/s11606016-3586-5.

2. Barry DT, et al. Pain and associated substance Use among opioid dependent individuals seeking office-based treatment with buprenorphinenaloxone: a needs assessment study. Am J Addict / Am Acad Psychiatr Alcohol Addict. 2013;22(3):212-217.

3. Rosenblum A, et al. Prevalence and characteristics of chronic pain among chemically dependent patients in methadone maintenance and residential treatment facilities. [see comment]. JAMA. 2003;289(18):2370-8.

4. Kuehn BM. Opioid prescriptions soar: increase in legitimate use as well as abuse. JAMA. 2007;297(3):249-51

This comment refers to the article available at: $h$ ttp://dx.doi.org/10.1007/ s11606-016-3586-5

Received May 8, 2015

Revised July 24, 2015

Accepted December 4, 2015

Published online March 7, 2016 